\title{
Correction: Prevalence of total hip and knee arthroplasty in former National Football League players: comparison with the general US population and other populations of professional athletes
}

Tenforde AS, Cortez B, Baker J, et al. Prevalence of total hip and knee arthroplasty in former National Football League players: comparison with the general US population and other populations of professional athletes. BMJ Open Sport \& Exercise Medicine 2020;6:e000833. doi: 10.1136/bmjsem-2020-000833

The article has been corrected since it was published online. An error was identified in the figure legend. The color for the bars graphs was incorrectly presented with the knee and hip arthroplasty colors in reverse. The figure was corrected to reflect accurate legend.

\section{Prevalence of Hip and Knee Replacement in US General Population and FPHS Cohort}

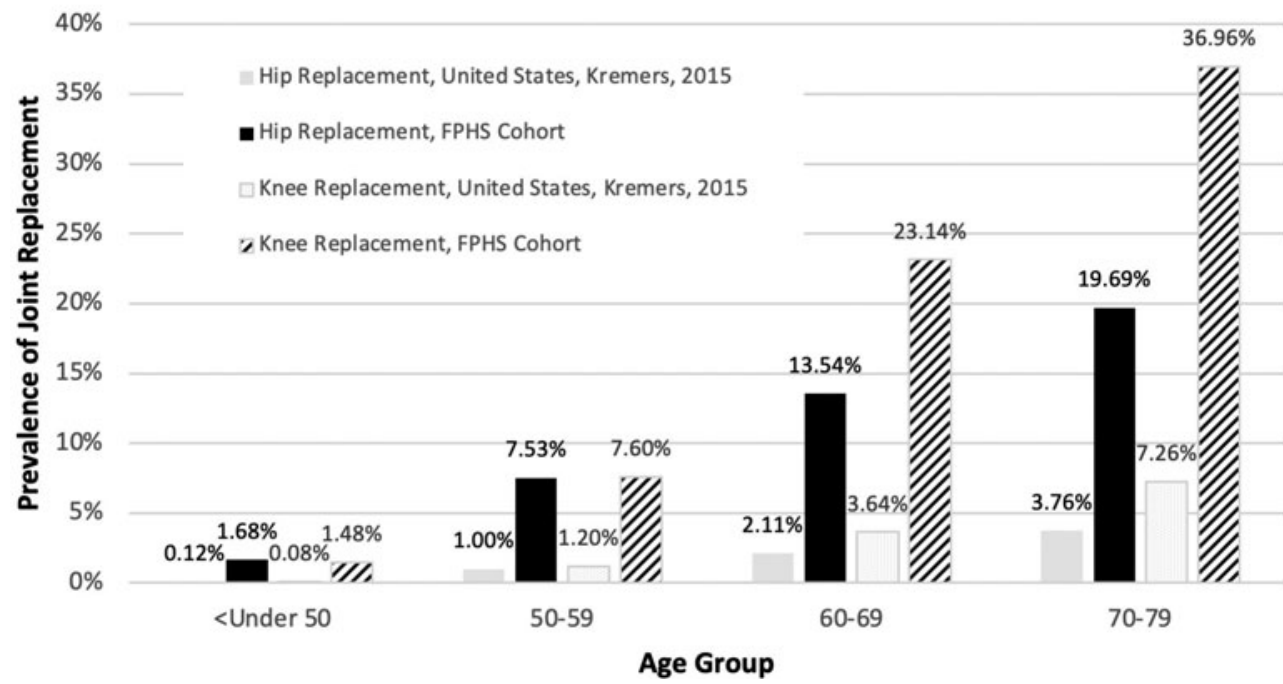

Figure 1 Prevalence of total knee arthroplasty and total hip arthroplasty was reported by age category of former NFL Players with the Football Players Health Study (FPHS) cohort and general US population. Knee arthroplasty was more common that hip arthroplasty for both populations. Arthroplasty was more common for FPHS cohort than general US population across all ages. NFL, National Football League.

(c) Author(s) (or their employer(s)) 2020. Re-use permitted under CC BY-NC. No commercial re-use. See rights and permissions. Published by BMJ.

BMJ Open Sp Ex Med 2020;0:1. doi:10.1136/bmjsem-2020-000833corr1

A) Check for updates 